\title{
$\beta$-Hydroxybutyrate induces bovine hepatocyte apoptosis via an ROS-p38 signaling pathway
}

\author{
Yuxiang Song, ${ }^{1} \mathrm{Na} \mathrm{Li},{ }^{1}$ Jingmin Gu, Shoupeng Fu, Zhicheng Peng, Chenxu Zhao, Yuming Zhang, Xiaobing Li, \\ Zhe Wang, Xinwei Li, ${ }^{2}$ and Guowen Liu ${ }^{2}$ \\ Key Laboratory of Zoonosis, Ministry of Education, College of Veterinary Medicine, Jilin University, 5333 Xi'an Road, Changchun, Jilin, \\ 130062, China
}

\begin{abstract}
$\beta$-Hydroxybutyrate (BHB) is an important indicator for metabolic disorders in dairy cows, such as ketosis and fatty liver. Dairy cows with ketosis display oxidative stress that may be associated with high levels of BHB. The purpose of this study was to demonstrate a correlation between the high levels of BHB and oxidative stress in dairy cows with ketosis, and to investigate the molecular mechanisms underlying oxidative damage in bovine hepatocytes. The results showed that dairy cows with ketosis exhibited oxidative stress and liver damage, which was significantly correlated with plasma BHB. Similarly, high concentrations of BHB increased the oxidative stress of cow hepatocytes in vitro, resulting in the phosphorylation and activation of p38 mitogen-activated protein kinase (MAPK), which led to increased expression, nuclear localization, and transcriptional activity of p53 and decreased Nrf2 in bovine hepatocytes. High concentrations of BHB significantly increased the expression of proapoptotic genes and significantly inhibited the expression of antiapoptotic genes. Finally, high concentrations of BHB promoted apoptosis in bovine hepatocytes. N-Acetyl-L-cysteine, glucose, and SB203580 (p38 inhibitor) significantly attenuated BHB-induced apoptotic damage in hepatocytes. These results indicate that BHB induces bovine hepatocyte apoptosis through the ROS-p38-p53/Nrf2 signaling pathway.
\end{abstract}

Key words: dairy cows, ketosis, oxidative stress, liver injury

\section{INTRODUCTION}

Cows experience metabolic changes during the transition period when an inadequate energy supply occurs

\footnotetext{
Received March 25, 2016.

Accepted June 26, 2016.

${ }^{1}$ Yuxiang Song and Na Li contributed equally to this study.

${ }^{2}$ Corresponding authors: lixinwei100@126.com and liuguowen2008 @163.com
}

due to a reduction in DMI. However, increased energy demands are necessary for lactation. Thus, transition dairy cows are often in a state of negative energy balance (NEB; Wathes et al., 2011; Li et al., 2015). Negative energy balance initiates fat mobilization and a subsequent increase in the concentration of nonesterified fatty acids (NEFA) and BHB in the blood (Song et al., 2014). $\beta$-Hydroxybutyrate is the main form of ketone body in dairy cows and is a result of incomplete oxidation of NEFA in the liver cells (Loor et al., 2007). It is known that the metabolic ability of BHB in the liver of dairy cows is limited. Therefore, excessive BHB accumulates in the liver and blood and then induces hyperketonemia. Furthermore, BHB and NEFA are 2 major diagnostic indicators of ketosis (Shi et al., 2014), and BHB has a higher diagnostic value for ketosis than NEFA in postpartum cows (Duffield, 2000). The plasma concentration of BHB in normal dairy cows is less than $1.2 \mathrm{mM}$; however, if subclinical or clinical ketosis develops BHB levels will exceed 1.2 or $1.5 \mathrm{~m} M$, respectively (Iwersen et al., 2013).

High concentrations of $\mathrm{BHB}$ have been reported to affect milk production and the performance of dairy cows (McArt et al., 2013) and increase the incidence of mastitis and endometritis in perinatal cows (Hammon et al., 2006; LeBlanc et al., 2011). Ketone bodies, including $\mathrm{BHB}$, as a substrate for oxidation and a precursor of fat synthesis, increase the production of ROS by promoting oxidation in the mitochondrial respiratory chain (Hawkins and Biebuyck, 1979). Pedernera et al. (2010) detected indicators of energy balance, including NEFA, BHB, and glucose (GLU), as well as some oxidative indexes. Those authors found that oxidative stress existed in perinatal cows and was related to NEFA, BHB, and NEB. Some evidence exists that $\mathrm{BHB}$ can increase the reactive oxygen species (ROS) content in bovine hepatocytes (Shi et al., 2014). The ROS generated by BHB may induce secondary hits to the liver and cause hepatocyte injury. Tharwat et al. (2012a,b) found hepatocyte apoptosis in perinatal cows with fatty livers accompanied by a sharp rise in serum BHB concentrations, which might be related to their 
lipid toxicity; however, the exact molecular mechanism is unclear.

Studies have shown that p38 mitogen-activated protein kinase (MAPK) is a sensor of oxidative stress and can be activated by intracellular ROS (Tormos et al., 2013). Importantly, the activation of p38 MAPK regulates the downstream apoptosis-related sensitive transcription factors, such as tumor protein p53 and nuclear factor-E2-related factor 2 (Nrf2), in response to oxidative stress (Liu et al., 2009; Circu and Aw, 2010). p53 is a multifunctional protein at the crossroad between DNA damage and apoptosis and has an important role in controlling cellular responses to many stress signals (She et al., 2000); Nrf2 is also a key oxidative stress regulatory factor and functions through the capture and release from a Keap-1/Nrf2 complex (Jaiswal, 2004). Gessner et al. (2013) showed that Nrf2 was activated in the liver of dairy cows during the periparturient phase to protect the liver against the deleterious effects of cytokines and ROS. The relationship between ROS, Nrf2, and p38 is cell type- and stimulus-dependent, and how these factors affect each other in transition period cows with high plasma BHB concentrations is unclear.

Ketotic cows exhibit oxidative stress, hepatic injury, and high blood BHB concentrations. It is of great interest to clarify the relevant mechanisms underlying BHB, oxidative stress, and hepatic injury in ketotic cows; however, the relationship between BHB and hepatic injury has not been elucidated in ketotic cows or even in humans. Therefore, the objective of our study was to investigate the hypothesis that high concentrations of BHB activate the p38 MAPK pathway and then induce bovine hepatic apoptotic injury.

\section{MATERIALS AND METHODS}

\section{In Vivo Experiments}

Animals. This protocol was approved by the Ethics Committee on the Use and Care of Animals of Jilin University (Changchun, China). Dairy cows were selected from an 8,000-cow ecology dairy farm located in Changchun City, Jilin Province, China, to match the breed, age, milk production, and BCS in each group. Forty-five lactating Holstein multiparous cows were divided into the healthy cow group (15 cows), the subclinical ketosis cow group (15 cows), and the ketosis cow group (15 cows) according to clinical symptoms of ketosis and blood BHB and GLU concentrations. Subclinical ketosis cows had plasma BHB concentrations between 1.2 and $1.5 \mathrm{mM}$. Clinical ketosis cows had plasma BHB concentrations greater than $1.5 \mathrm{~m} M$. Healthy cows had plasma BHB concentrations less than
$0.6 \mathrm{~m} M$ and glucose concentration greater than $3.5 \mathrm{mM}$. No significant change in the temperature, pulse rate, and respiratory rate were noted in clinical examination. Blood was collected from the jugular vein before the morning feeding and then centrifuged at $1,000 \times g$ for $5 \mathrm{~min}$. The serum was stored at $-80^{\circ} \mathrm{C}$ for biochemical parameter analysis.

Blood Biochemical Parameters Assay In Vivo. The serum oxidation and antioxidant parameters of total antioxidant capacity (TAC; visible light method), malondialdehyde (MDA), glutathione (GSH), and glutathione disulfide (GSSG) were measured using biochemical kits according to the manufacturer's instructions (Nanjing Jian Cheng Institute of Bioengineering, Nanjing, China). In the TAC detection kit, the antioxidant defense system consists of enzymatic and nonenzymatic antioxidants, which reduce $\mathrm{Fe}^{3+}$ to $\mathrm{Fe}^{2+}$. Total antioxidant capacity was measured depending on the reaction of phenanthroline and $\mathrm{Fe}^{2+}$ using a spectrophotometer at $520 \mathrm{~nm}$. One TAC unit was defined as the capability of increasing 0.01 optical density value in $1 \mathrm{~mL}$ of homogenate per min. In the MDA detection kit, MDA level was measured by the thiobarbituric acid method. The amounts of lipid peroxides were measured as the production of MDA; absorbance was measured at $532 \mathrm{~nm}$ by spectrometry. The activities of catalase (CAT), superoxide dismutase (SOD), and glutathione peroxidase (GSH-Px) were measured using biochemical kits according to the manufacturer's instructions (Nanjing Jian Cheng Institute of Bioengineering). In addition, serum liver function parameters, including alanine aminotransferase (ALT), alkaline phosphatase (ALP), and aspartate transaminase (AST), were detected using biochemical kits (Beijing Strong Biotechnologies Inc., Beijing, China) according to the manufacturer's instructions. We analyzed the oxidation and antioxidant state and the correlation between oxidative stress and plasma BHB in dairy cows with or without ketosis. The biological replicate of each parameter was 15 times.

\section{In Vitro Experiments}

Hepatocyte Isolation and Culture. In vitro, the hepatocytes were isolated from the liver of newborn Holstein cow by the collagenase perfusion method as previously described (Liu et al., 2014; Li et al., 2015). The caudate lobe of the liver was quickly moved to a bench. The bloodstains on the liver surface were removed with perfusion solution $\left(37^{\circ} \mathrm{C}\right)$. Blood vessels were perfused with perfusion solution $\left(37^{\circ} \mathrm{C}\right)$ until the liquid became clear. Then, the liver was perfused with digestion solution to dissociate liver tissue structure until the liquid 
became muddy. The liver was cut open and the liver capsule, blood vessels, fat, and connective tissue were removed using forceps and scissors. The liver parenchyma was cut into pieces and filtered sequentially with $100(150 \mu \mathrm{m}), 200(75 \mu \mathrm{m})$, and 400 mesh $(37.5 \mu \mathrm{m})$ cell sieves. Trypan blue dye (Sigma-Aldrich, St Louis, MO) exclusion method was used to assess cell viability. The percentage of viable cells was almost $97 \%$. The cell density was adjusted to $1 \times 10^{6}$ cells $/ \mathrm{mL}$ using adherent medium. The hepatocytes were incubated at $37^{\circ} \mathrm{C}$ in $5 \% \mathrm{CO}_{2}$. After $4 \mathrm{~h}$, the adherent medium was replaced with growth medium containing $10 \%$ fetal bovine serum. The growth medium was replaced every 24 $\mathrm{h}$. The perfusion solution, digestion solution, adherent medium, and growth medium were prepared as per our previous study (Liu et al., 2014).

Preparation and Treatment of $\mathrm{BHB}$. The concentrations of BHB used in our study were selected according to the normal and pathological hematology standards for dairy cows with or without ketosis (Iwersen et al., 2013). $\beta$-Hydroxybutyrate was prepared as previously described (Shi et al., 2014).

Before BHB treatment, the cells were serum-starved overnight. To avoid the change of $\mathrm{pH}$ in medium, BHB was used in its sodium salt: sodium $\beta$-hydroxybutyrate. The hepatocytes were treated with $0,0.6,1.2$, and 2.4 $\mathrm{m} M$ BHB [with or without $10 \mu M$ SB203580, $10 \mathrm{~m} M$ $\mathrm{N}$-acetyl-L-cysteine (NAC), and $4 \mathrm{~m} M$ GLU] for $9 \mathrm{~h}$; SB203580 is an inhibitor of p38 (Selleck Chemicals LLC, Houston, TX) and NAC is an antioxidant that attenuates oxidative stress (Sigma-Aldrich, St Louis, $\mathrm{MO})$.

\section{Apoptosis Assay}

Hepatocyte apoptosis was detected after BHB treatment. In brief, the hepatocytes were treated with 0 , $0.6,1.2$, and $2.4 \mathrm{mM}$ BHB for $24 \mathrm{~h}$ (with or without SB203580, NAC, and GLU). The hepatocytes were separated by trypsin digestion and stained using Annexin V-fluorescein isothiocyanate (FITC)/propidium iodide (PI) (BD Biosciences, San Jose, CA) and then analyzed using fluorescence microscopy and flow cytometry. Each treatment was replicated 6 times.

\section{Western Blot Analysis}

The total protein and nuclear proteins of the hepatocytes were extracted according to the manufacturer's instructions (Sangon Biotech Co. Ltd., Shanghai, China). The target proteins were separated by PAGE and electrotransferred onto polyvinylidene fluoride (PVDF) membranes. Then, we blocked the PVDF membranes with 5\% BSA in Tris-buffered saline with Tween (Sigma-Aldrich) for $2 \mathrm{~h}$ at $4^{\circ} \mathrm{C}$ and hybridized them with specific antibodies, including cleaved caspase 3, cleaved caspase 9, p-p38 (Cell Signaling Technology, Danvers, MA), Bax, Nrf2 (Santa Cruz Biotechnology, Santa Cruz, CA), caspase 3, p38, Bcl-2, $\beta$-actin, Histone H3, and p53 (Abcam, Cambridge, MA). The PVDF membranes were then incubated with secondary antibodies. Immunoreactive bands were detected with an enhanced chemiluminescence solution (Beyotime Biotechnology Inc., Shanghai, China). The bands were detected and analyzed using a Protein Simple Imager (Protein Simple, San Jose, CA). Western blot experiment was replicated 3 times in each group.

\section{p38a Enzyme Activity Detection Assay}

p38 $\alpha$ enzyme activity in hepatocytes was detected after treatment with BHB using a p38 $\alpha$ kinase activity spectrophotometric quantification kit (GENMED Scientifics Inc., Arlington, MA). The hepatocytes were lysed in the lysis buffer. The mixture was vortexed for $15 \mathrm{~s}$, incubated in an ice bath for $30 \mathrm{~min}$, and then centrifuged at $1,600 \times g$ for $5 \mathrm{~min}$ at $4^{\circ} \mathrm{C}$. The absorbance of the supernatant was detected using a spectrophotometer (ELX 800, BioTek, Winooski, VT). p38a activity detection was replicated 6 times in each group.

\section{Determination of Intracellular ROS Concentrations and Oxidative Stress Indexes}

After BHB treatment, hepatocytes were incubated with dichlorofluorescein diacetate (Beyotime Biotechnology Inc.) for $30 \mathrm{~min}$ at $37^{\circ} \mathrm{C}$. The fluorescence intensity of the hepatocytes was measured by flow cytometry (Becton Dickinson, Franklin Lakes, NJ). The content of TAC, MDA, GSH, and GSSG and the activities of CAT, SOD, and GSH-Px were measured using biochemical kits (Nanjing Jian Cheng Institute of Bioengineering) according to the manufacturer's instructions. Intracellular ROS determination was replicated 3 times in each group.

\section{Quantitative Real-Time PCR Assay}

Total RNA was extracted from the hepatocytes using Trizol (TaKaRa Biotechnology Co. Ltd., Shiga, Japan). The quality of the RNA extracted was assessed by electrophoresis (1\% agarose gels) before reverse transcription into cDNA (TaKaRa Biotechnology Co. Ltd.). The primers for the target genes were designed using Primer Express software (PE Applied Biosystems Inc., Foster City, CA) and are shown in Table 1. We evaluated 
Table 1. Plasma energy metabolism, liver function, and oxidation and antioxidant indexes in dairy cows with or without ketosis ${ }^{1}$

\begin{tabular}{lccc}
\hline Test indexes & $\begin{array}{c}\text { Healthy cows } \\
(\mathrm{n}=15)\end{array}$ & $\begin{array}{c}\text { Subclinical ketosis cows } \\
(\mathrm{n}=15)\end{array}$ & $\begin{array}{c}\text { Ketosis cows } \\
(\mathrm{n}=15)\end{array}$ \\
\hline Energy metabolism indexes & & & \\
BHB $(\mathrm{m} M)$ & $0.49 \pm 0.12$ & $1.26 \pm 0.19^{\mathrm{A}}$ & $3.09 \pm 0.12^{\mathrm{A}}$ \\
Nonesterified fatty acids $(\mathrm{m} M)$ & $0.23 \pm 0.09$ & $0.60 \pm 0.11^{\mathrm{A}}$ & $1.16 \pm 0.71^{\mathrm{A}}$ \\
Glucose $(\mathrm{m} M)$ & $3.69 \pm 0.68$ & $3.21 \pm 0.32^{\mathrm{A}}$ & $2.75 \pm 0.41^{\mathrm{A}}$ \\
Liver function indexes & $21.8 \pm 3.3$ & $27.4 \pm 3.2^{\mathrm{a}}$ & $32.5 \pm 7.8^{\mathrm{A}}$ \\
Alanine aminotransferase (U/L) & $87.7 \pm 13.9$ & $105.2 \pm 15.3^{\mathrm{a}}$ & $136.4 \pm 23.7^{\mathrm{A}}$ \\
Aspartate transaminase $(\mathrm{U} / \mathrm{L})$ & $30.7 \pm 5.7$ & $45.7 \pm 6.6^{\mathrm{A}}$ & $46.8 \pm 7.2^{\mathrm{A}}$ \\
Alkaline phosphatase $(\mathrm{U} / \mathrm{L})$ & & & \\
Oxidation and antioxidant indexes & $93.6 \pm 7.6$ & $83.8 \pm 4.1^{\mathrm{a}}$ & $73.9 \pm 9.8^{\mathrm{A}}$ \\
Superoxide dismutase $(\mathrm{U} / \mathrm{mL})$ & $3.8 \pm 0.6$ & $2.7 \pm 0.4^{\mathrm{A}}$ & $2.3 \pm 0.6^{\mathrm{A}}$ \\
Total antioxidant capacity $(\mathrm{U} / \mathrm{mL})$ & $2.1 \pm 0.3$ & $3.5 \pm 0.7^{\mathrm{A}}$ & $3.6 \pm 0.6^{\mathrm{A}}$ \\
Malondialdehyde $(\mathrm{nmol} / \mathrm{mL})$ & $4.6 \pm 0.6$ & $4.3 \pm 0.5$ & $2.7 \pm 0.7^{\mathrm{A}}$ \\
Glutathione $(\mu \mathrm{\mu mol} / \mathrm{L})$ & $9.50 .7 \pm 1.1$ & $0.87 \pm 0.24^{\mathrm{A}}$ & $0.98 \pm 0.19^{\mathrm{A}}$ \\
Glutathione disulfide $(\mu \mathrm{mol} / \mathrm{L})$ & $105.8 \pm 15.2$ & $98.7 \pm 0.8^{\mathrm{A}}$ & $3.5 \pm 0.6^{\mathrm{A}}$ \\
Glutathione:glutathione disulfide & $1.6 \pm 0.7$ & $1.2 \pm 0.6$ & $83.7 \pm 8.9^{\mathrm{A}}$ \\
Glutathione peroxidase $(\mathrm{U} / \mathrm{mL})$ & & $0.8 \pm 0.4^{\mathrm{A}}$ \\
Catalase $(\mathrm{U} / \mathrm{mL})$ & & & \\
\hline
\end{tabular}

${ }^{\mathrm{A}, \mathrm{a}}$ Superscripts indicate significant differences compared with healthy cows: ${ }^{\mathrm{A}} P<0.01 ;{ }^{\mathrm{a}} P<0.05$.

${ }^{1}$ Results are expressed as means \pm SEM.

mRNA expression levels using quantitative real-time (qRT) PCR technology with the SYBR Green QuantiTect RT-PCR Kit (TaKaRa Biotechnology Co. Ltd.) and a 7500 Real-Time PCR System (Applied Biosystems Inc.). The relative expression of each target gene was normalized to $\beta$-actin. The qRT-PCR experiment was performed 6 times in each group.

\section{Immunofluorescence Assay}

We used an immunofluorescence assay (IF) to detect the cellular localization of p53 and Nrf2. Hepatocytes were treated with BHB; we fixed the hepatocytes with $10 \%$ formalin in $0.1 \%$ PBS for 20 min. Antigen retrieval was performed using EDTA- $\mathrm{Na}_{2}$ at $95^{\circ} \mathrm{C}$ for 5 min. The hepatocytes were permeabilized using $0.1 \%$ Triton X-100 (Beyotime Biotechnology Inc.) and incubated with specific antibodies overnight at $4^{\circ} \mathrm{C}$. Then, the hepatocytes were incubated with secondary antibodies for $30 \mathrm{~min}$. We stained the hepatocyte nuclei with Hoechst 33258 (Beyotime Biotechnology Inc.) for $20 \mathrm{~min}$. Finally, the coverslips were sealed with glycerol and the samples were imaged using laser confocal microscopy (FV500, Olympus, Tokyo, Japan). The IF experiments were separated repeated 3 times, each time at least 3 watching zone were selected for judgement.

\section{Electrophoretic Mobility Shift Assay}

We used an electrophoretic mobility shift assay (EMSA) to detect the transcriptional activity of p53 and Nrf2. Hepatocyte nuclear proteins were extracted using a nuclear protein extraction kit (Sangon Biotech Co. Ltd., Shanghai, China). The special probe recognition sequences were 5'-TACAGAACATGTCTAAGCATGCTGGGGACT-3' for p53 and 5'-ACTGAGGGTGACTCAGCAAAATC-3' for Nrf2. The probes were labeled with biotin by incubating them together for $30 \mathrm{~min}$ at $37^{\circ} \mathrm{C}$. The binding reaction was performed using the Lightshift EMSA Optimization and Control Kit (Pierce Biotechnology Inc., Rockford, IL). We collected hepatocyte nuclear proteins after BHB treatment for $9 \mathrm{~h}$. The DNA-protein complexes were separated by electrophoresis with nondenaturing $6.5 \%$ polyacrylamide Tris-borate-EDTA gels and then electro-transferred onto a nylon membrane that was crosslinked using a UV light crosslinker (Cany Precision Instruments Co. Ltd., Shanghai, China). We detected the biotin-labeled probe using a chemiluminescence solution (Pierce Biotechnology Inc.). The band intensity was measured after exposing the blots to x-ray film using a LAS3000 Bioimage analyzer (Fuji Photo Film Co., Beijing, China).

\section{Statistical Analysis}

The data were analyzed using one-way ANOVA followed by Duncan's multiple range test (SPSS 13.0 software; SPSS Inc., Chicago, IL). Results were expressed as means \pm standard error of the means. A $P$-value of less than 0.05 was considered statistically significant, and values less than 0.01 were considered markedly significant. 
Table 2. Correlations between BHB and oxidation and antioxidant indexes in plasma of dairy cows with or without ketosis

\begin{tabular}{lcccccrr}
\hline $\begin{array}{l}\text { Test } \\
\text { indexes }\end{array}$ & $\begin{array}{c}\text { Superoxide } \\
\text { dismutase }\end{array}$ & $\begin{array}{c}\text { Total } \\
\text { antioxidant } \\
\text { capacity }\end{array}$ & Malondialdehyde & Glutathione & $\begin{array}{c}\text { Glutathione } \\
\text { disulfide }\end{array}$ & $\begin{array}{c}\text { Glutathione: } \\
\text { glutathione } \\
\text { disulfide }\end{array}$ & $\begin{array}{c}\text { Glutathione- } \\
\text { peroxidase }\end{array}$ \\
r & -0.653 & -0.698 & 0.563 & -0.710 & 0.782 & -0.701 & -0.697 \\
$P$-value & 0.005 & 0.002 & 0.005 & 0.000 & 0.000 & 0.000 & 0.004 \\
\hline
\end{tabular}

\section{RESULTS}

\section{Oxidative Stress and Liver Injury Correlated with BHB}

Dairy cows with ketosis displayed severe NEB. As shown in Table 2, compared with healthy cows, serum levels of BHB and NEFA increased; however, GLU decreased significantly in cows with subclinical and clinical ketosis. Serum MDA contents were significantly higher in ketotic cows than in healthy cows. The GSH content was significantly decreased but GSSG was significantly increased, resulting in a significant decrease in ratio of GSH and GSSG in subclinical ketosis and ketosis cows (Table 2). Furthermore, the content of TAC, together with the activities of SOD, GSH-Px, and CAT were significantly decreased in subclinical ketosis and ketosis cows (Table 2). These results indicate that ketotic cows exhibit oxidative stress. According to the results of the liver function indexes, compared with healthy cows, ALT, ALP, and AST activities were significantly higher in ketotic cows than in healthy cows (Table 2). These results indicate that dairy cows with subclinical or clinical ketosis exhibit hepatic injury.

\section{Correlation of BHB and Oxidative Stress in Transition Dairy Cows}

We analyzed the correlation between BHB and some oxidation and antioxidant parameters. As shown in Ta- ble 3, the results showed that BHB levels had a positive relationship with oxidative indicators MDA and GSSG, and negative relationship with SOD, TAC, GSH-Px, GSH, GSH:GSSG, and CAT. These results reasoned us to speculate that high levels of BHB might be associated the severe hepatic oxidative stress in ketotic cows.

\section{BHB-Induced Hepatocyte Apoptosis Through Oxidative Stress}

To investigate whether $\mathrm{BHB}$ induces hepatocytes oxidative stress, hepatocytes were treated with different concentrations of BHB. As shown in Figure 1, high concentrations of BHB decreased the TAC content and the activities of GSH-Px, CAT, and SOD and increased the MDA content in hepatocytes (Figure 1A). Furthermore, high concentrations of BHB decreased GSH and increased GSSG content; as a result, the ratio of GSH to GSSG decreased (Figure 1B). Relative to the control group $(0 \mathrm{mM})$, the 1.2 and $2.4 \mathrm{~m} M$ BHB treatment groups had markedly elevated ROS levels and GLU was able to attenuate this effect (Figure 1C). Collectively, these results indicate that high levels of $\mathrm{BHB}$ induce hepatocyte oxidative stress, which further confirms our in vivo results. Importantly, the hepatocyte apoptotic rate was significantly increased in the 1.2 and $2.4 \mathrm{mM}$ BHB groups, but was inhibited by NAC and GLU (Figure 2). These results indicate that high concentra-

Table 3. The primer sequences of designated genes

\begin{tabular}{lllc}
\hline Gene & Sequence number & Primer sequences $\left(5^{\prime}-3^{\prime}\right)$ & $\begin{array}{c}\text { Length } \\
(\mathrm{bp})\end{array}$ \\
\hline$\beta$-Actin & BC 142413.1 & $\begin{array}{l}\text { Forward: GCCCTGAGGCTCTCTTCCA } \\
\text { Reverse: GCGGATGTCGACGTCACA }\end{array}$ & 101 \\
p38 MAPK & NM_001102174.1 & $\begin{array}{l}\text { Forward: AAGTAGCCAGGTTGTCG } \\
\text { Reverse: AGAGGATGGCGATGA }\end{array}$ & 156 \\
Caspase 3 & NM_001077840 & $\begin{array}{l}\text { Forward: AGAACTTGGTGGTCCATACA } \\
\text { Reverse: CTCAACCCGTCTCCCTTTAT }\end{array}$ & 242 \\
Caspase 9 & NM_001205504.1 & $\begin{array}{l}\text { Forward: TTCCCCCTTATTTTGCTC } \\
\text { Reverse: ACGGCTCCCACCCCAGTC }\end{array}$ & 148 \\
Nrf2 & NM_001011678 & $\begin{array}{l}\text { Forward: GCCCTCACTGGATAAAGAA } \\
\text { Reverse: CATGCCGTTGCTGGTAC }\end{array}$ & 202 \\
p53 & NM_174201.2 & $\begin{array}{l}\text { Forward: GAGCACTGCCTACCAACA } \\
\text { Reverse: CATCCAGAGCATCCTTCA }\end{array}$ & 150 \\
Bax & XM_004767368.1 & $\begin{array}{l}\text { Forward: CCTTTTGCTTCAGGGTTC } \\
\text { Reverse: GCTCAGCTTCTTGGTGGAT }\end{array}$ & 109 \\
Bcl-2 & NM_001166486 & $\begin{array}{l}\text { Forward: TGACCGAGTACCTGAACCG } \\
\text { Reverse: CAGCCAGGAGAAATCAAACA }\end{array}$ & 116 \\
& & & \\
\hline
\end{tabular}


tions of BHB induce hepatocyte apoptosis by causing oxidative stress.

\section{BHB-Induced Hepatocyte Apoptosis is Mediated by the ROS-p38 Signaling Pathway}

We determined the activity and mRNA and protein expression of p38. The results showed that BHB increased p38 activity (Figure 3A) and mRNA (Figure 3B) and protein (Figure 3C) expression in a dosedependent manner; however, the mRNA and protein expression of p38 decreased significantly in the NAC and GLU treatment groups $(P<0.01$; Figure $3 \mathrm{~B}$ and $3 \mathrm{D})$. Importantly, high concentrations of BHB promoted hepatocyte apoptosis and SB203580 (p38 inhibitor), NAC (an antioxidant), and GLU protected hepatocytes against the apoptosis caused by BHB (Figure 3E). These results indicate that the p38 signaling pathway is involved in the hepatocyte apoptosis caused by BHB.

The Bcl-2 family members and caspase expression play a vital role in cell apoptosis. Therefore, we determined the expression levels of Bax, Bcl-2, caspase 3, and caspase 9 . Relative to the control group, the mRNA levels of $B a x$, caspase 3 , and caspase 9 were significantly increased in the $2.4 \mathrm{mM}$ BHB treatment group (Figure 4A,C,D), whereas Bcl-2 decreased significantly in the $2.4 \mathrm{~m} M$ BHB treatment group (Figure 4B). Furthermore, BHB increased the protein expression of caspase 9 and Bax and promoted the decomposition and activation of caspase 3 and caspase 9 , whereas the protein expression level of Bcl-2 was decreased (Figure $4 \mathrm{E}-4 \mathrm{G}$ ). The SB203580, NAC, and GLU treatments were resistant to these BHB-induced effects at both the transcriptional and translational levels (Figure 4). Collectively, these results further indicate that BHBinduced apoptosis in hepatocytes is mediated by the p38 MAPK signaling pathway.

\section{p53 and Nrf2 in p38-Mediated Hepatocyte Apoptosis Caused by BHB}

p53 is a pivotal apoptosis regulation center that can be activated by p38. The transcription and nuclear protein levels of p53 were elevated in the $2.4 \mathrm{mM}$ BHB treatment group (Figure $5 \mathrm{~A}$ and $5 \mathrm{~B}$ ). Relative to the $2.4 \mathrm{~m} M$ BHB treatment group, the groups treated with SB203580, NAC, and GLU showed decreased nuclear p53 protein levels (Figure 5A and 5B). The transcriptional activity and cellular localization of p53 were determined by EMSA and IF assays, respectively. Relative to the control group, $2.4 \mathrm{~m} M$ BHB increased p53 transcriptional activity and promoted p53 translocation to the nucleus. Compared with the $2.4 \mathrm{mM}$ BHB group, the SB203580, NAC, and GLU groups showed decreased p53 transcriptional activity and levels of nuclear translocation (Figure 5C and Figure 6). Collectively, these results suggest that BHB activates p38 and then increases the expression and transcriptional activity of p53, which promotes hepatocyte apoptosis.

The Nrf2 is an important transcription factor that is closely associated with cell antiapoptosis and regulates the expression of many antioxidant- and apoptosisrelated genes; Nrf2 also has a complex relationship with p38. Compared with the control group, the nuclear protein and mRNA expression levels of Nrf2 significantly decreased in the $2.4 \mathrm{~m} M$ BHB group (Figure $7 \mathrm{~A}$ and $7 \mathrm{~B}$ ). Compared with the $2.4 \mathrm{mM}$ BHB group, the nuclear protein level of Nrf2 increased significantly in the NAC, GLU, and SB203580 treatment groups (Figure $7 \mathrm{~A}$ and $7 \mathrm{~B}$ ). The transcriptional activity and cellular localization of Nrf2 were determined by EMSA and IF assays, respectively. The results were similar to the Nrf2 Western blot results (Figure 7B and Figure 8) and suggest that high levels of BHB $(2.4 \mathrm{mM})$ activate the p38 MAPK signaling pathway and, thus, inhibit the nuclear translocation and transcriptional activity of Nrf2.

\section{DISCUSSION}

Ketotic cows exhibited severe NEB and displayed high blood concentrations of BHB and low concentrations of GLU. Furthermore, the ability to use BHB is limited to the liver, resulting in the accumulation of excess BHB in the liver and blood (Grummer, 2008). In our study, we also found that dairy cows with subclinical or clinical ketosis showed a serious NEB. Perinatal cows, especially cows with ketosis, are in a state of high-intensity energy metabolism, which leads to oxidation and antioxidant imbalance, resulting in oxidative stress and injury. Evidence exists of the presence of oxidative stress in transition cows based on changes in plasma MDA and TAC (Castillo et al., 2005, 2006). Our results showed that the plasma oxidation product MDA was significantly increased in ketotic cows compared with the healthy cows. In addition, the TAC content, GSH-Px activities, CAT, and GSH-to-GSSG content ratio were significantly reduced in ketotic cows. These results suggest that dairy cows with subclinical or clinical ketosis exhibit oxidative stress, which agrees with previous studies. Excessive accumulation of BHB in the liver may cause liver damage, which may be related to oxidative stress in transitional dairy cows. Here, we found that the activities of ALT, AST, and ALP were significantly elevated in both subclinical and clinical ketosis cows compared 

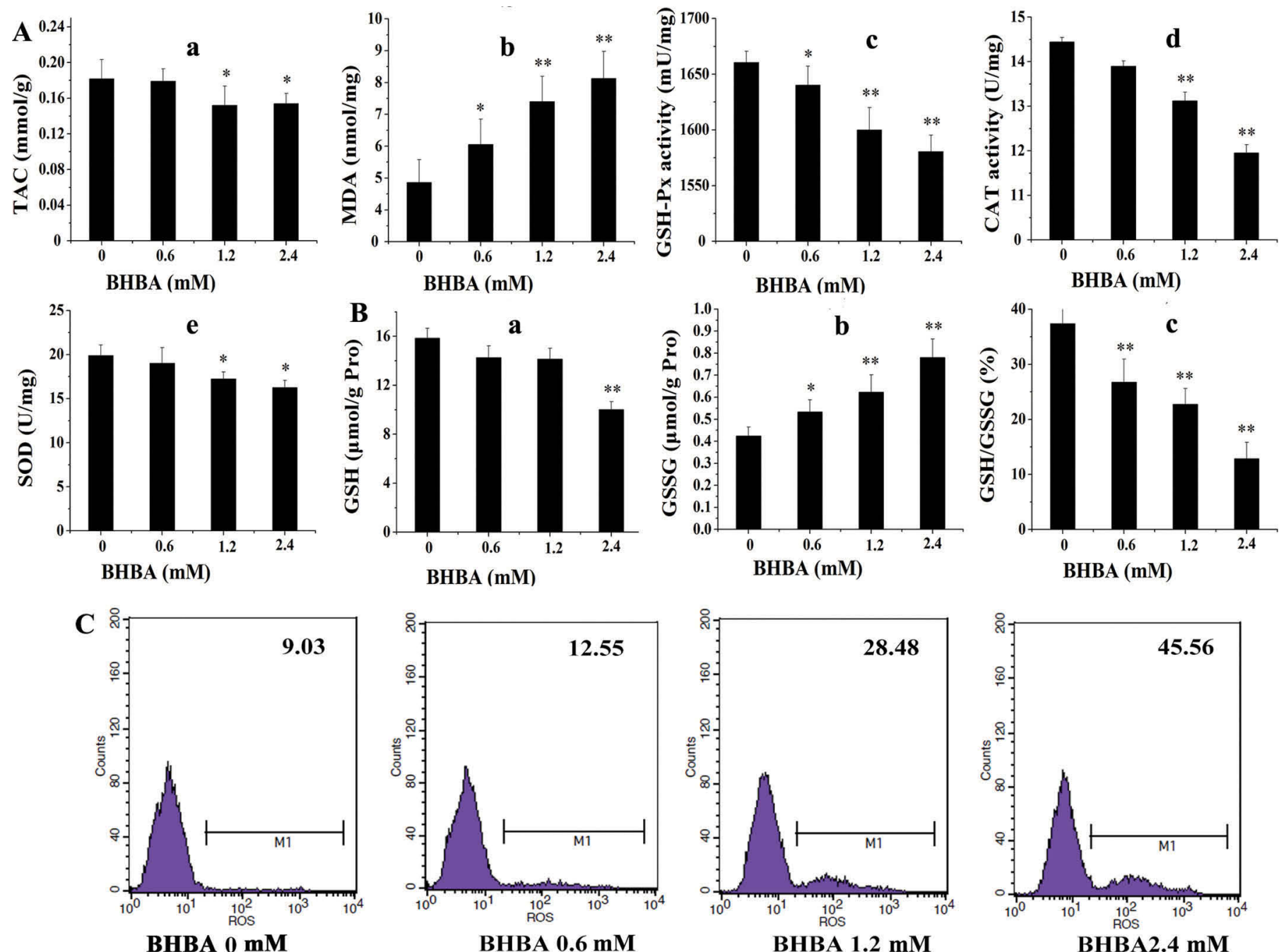

BHBA $0.6 \mathrm{mM}$
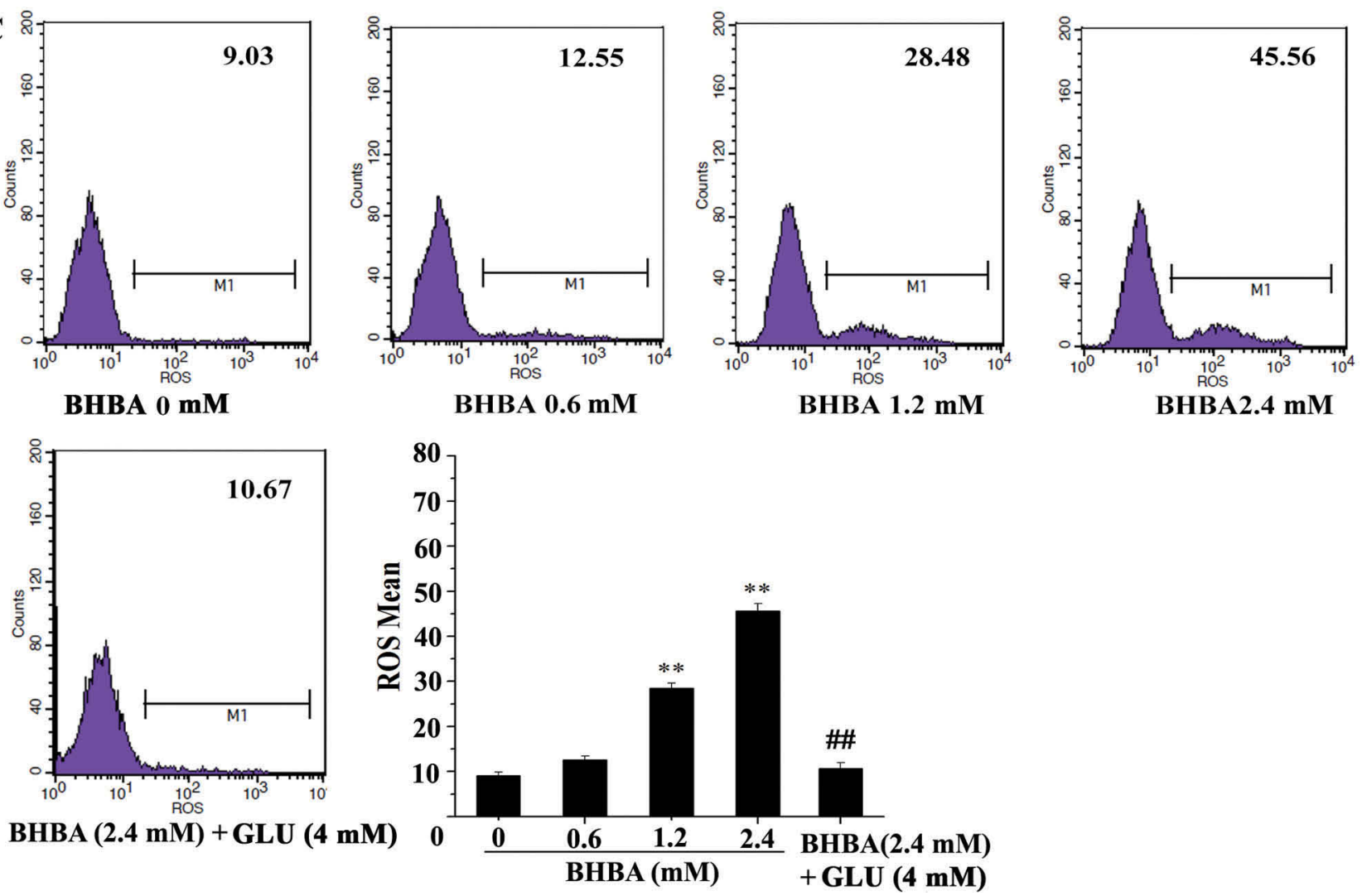

Figure 1. $\beta$-Hydroxybutyrate induces oxidative stress in bovine hepatocytes. The hepatocytes were treated with different concentrations of BHB and glucose (GLU; $4 \mathrm{mM}$ ). (A) The malondialdehyde (MDA) and total antioxidant capacity (TAC) contents and the glutathione peroxidase (GSH-Px), catalase (CAT), and superoxide dismutase (SOD) activities in bovine hepatocytes. (B) The glutathione (GSH) and glutathione disulfide (GSSG) contents and the GSH-to-GSSG ratio in bovine hepatocytes. (C) The reactive oxygen species (ROS) levels in bovine hepatocytes. The ROS levels were represented by the mean of fluorescence density determined by flow cytometry. Results were expressed as means \pm SEM. ${ }^{*} P<0.05,{ }^{* *} P<0.01$ versus the control group $(0 \mathrm{~m} M \mathrm{BHB})$; $\# P<0.05$, \#\#P<0.01 versus the $2.4 \mathrm{~m} M$ BHB group. M1 is the positive ROS expression zone. Color version available online. 


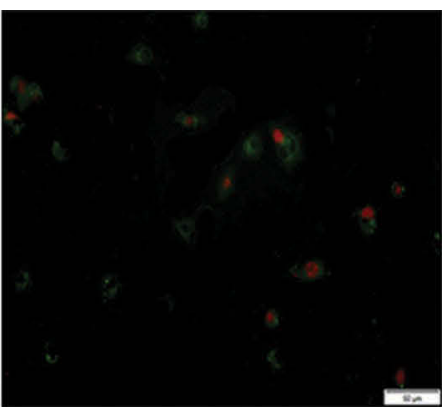

$\mathrm{BHB}(0 \mathrm{~m} M)$

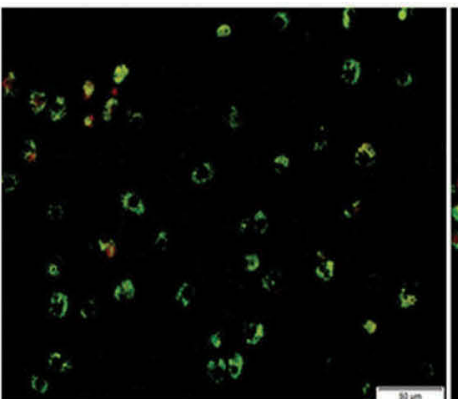

BHB $(2.4 \mathrm{~m} M)+\mathrm{NAC}(10 \mathrm{~m} M)$

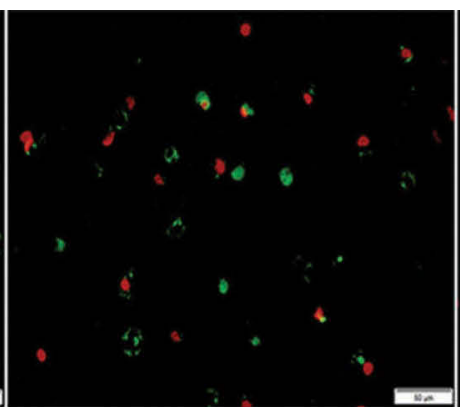

BHB $(0.6 \mathrm{mM})$

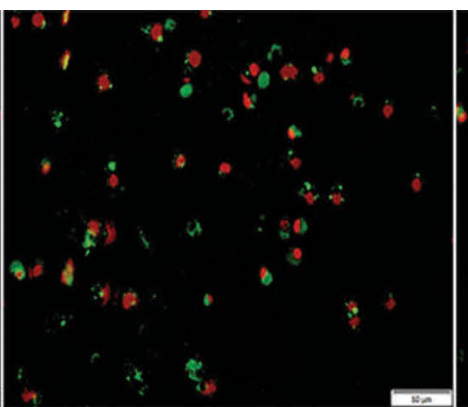

BHB (1.2 mM)

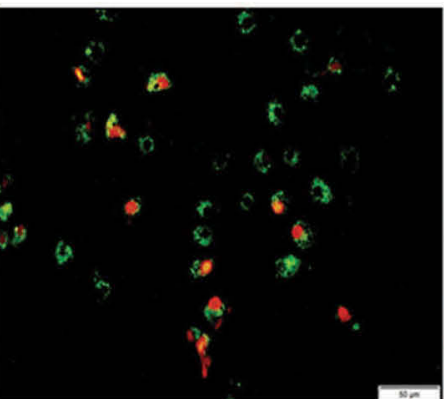

NAC $(10 \mathrm{~m} M)$

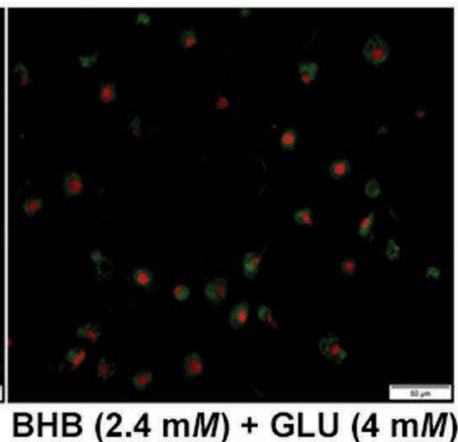

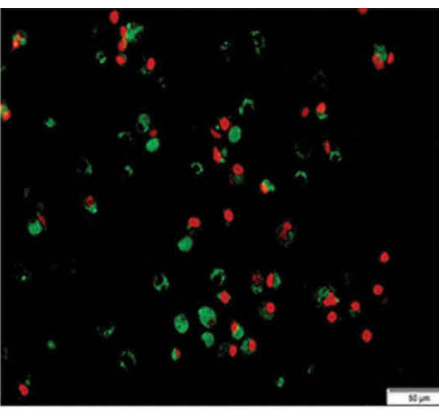

BHB (2.4 mM)

Figure 2. $\beta$-Hydroxybutyrate induces oxidative stress and subsequent hepatocyte apoptosis. The hepatocytes were treated with different concentrations of BHB $(0,0.6,1.2$, and $2.4 \mathrm{~m} M)$, BHB $(2.4 \mathrm{~m} M)$ and N-acetyl-L-cysteine (NAC; $10 \mathrm{~m} M)$, NAC $(10 \mathrm{~m} M)$, and BHB $(2.4 \mathrm{~m} M)$ and glucose (GLU; $4 \mathrm{mM}$ ). Apoptotic hepatocytes were stained with Annexin V-fluorescein isothiocyanate (FITC)/propidium iodide (PI) (BD Biosciences, San Jose, CA) and observed under a fluorescence microscope. Color version available online.

with those in healthy cows. These results indicate that cows with ketosis exhibit liver damage, which may be related to oxidative stress.

$\beta$-Hydroxybutyrate associates with oxidative stress, but its role in oxidative stress varies in different species and different tissues. $\beta$-Hydroxybutyrate has been reported to inhibit the oxidative stress caused by paraguat in HEK293 cells (Shimazu et al., 2013). Another study reported that physiological concentrations of BHB significantly improved the antioxidant capacity of nerve cells in mice, showing a neuroprotective function (Noh et al., 2006); however, unlike in the monogastric animals, BHB seems to promote oxidative stress in bovines. $\beta$-Hydroxybutyrate has been reported to reduce the activities of some antioxidant enzymes to promote oxidative stress in heifers (Wullepit et al., 2012), and had a positive correlation with MDA content in ketotic cows (Youssef et al., 2010). In our study, plasma BHB had a positive relationship with oxidative indicator MDA and GSSG, and negative relationship with SOD, TAC, GSH-Px, GSH, GSH:GSSG, and CAT in dairy cows with ketosis. In vitro, we found that BHB treatment also significantly increased the MDA and GSSG content, and markedly reduced the activity or content of SOD, TAC, GSH-Px, GSH, and CAT in bovine he- patocytes. These results indicate that BHB is a major induction factor for oxidative stress in ketosis and further confirm the results obtained from dairy cows with ketosis. The pathologic basis of ketosis is NEB; therefore, when we added BHB with GLU, the BHBmedicated ROS level was decreased in the hepatocytes. These results demonstrate that NEB is an indispensable factor of the development of liver damage induced by BHB.

Oxidative stress mediated by ROS can cause damage of proteins and nucleic acids, contributing to the apoptosis and inducing second hit (Walsh et al., 2007). We therefore further determined the effects of BHB on hepatocyte apoptosis by inducing oxidative stress. The results showed that high concentrations of BHB elevated the apoptotic rate of hepatocytes. Furthermore, we found that both GLU, the main energy supply in hepatocytes, and NAC, an antioxidant that can clear produced ROS, protected hepatocytes from the apoptosis caused by BHB. These results suggest that BHB can induce oxidative stress-mediated hepatocyte apoptosis. Dairy cows with ketosis are in a high-fat and low-glucose state. The glucose levels in cows are at a relatively low level in ketosis cows, which cannot protect hepatocytes from oxidative damage. 

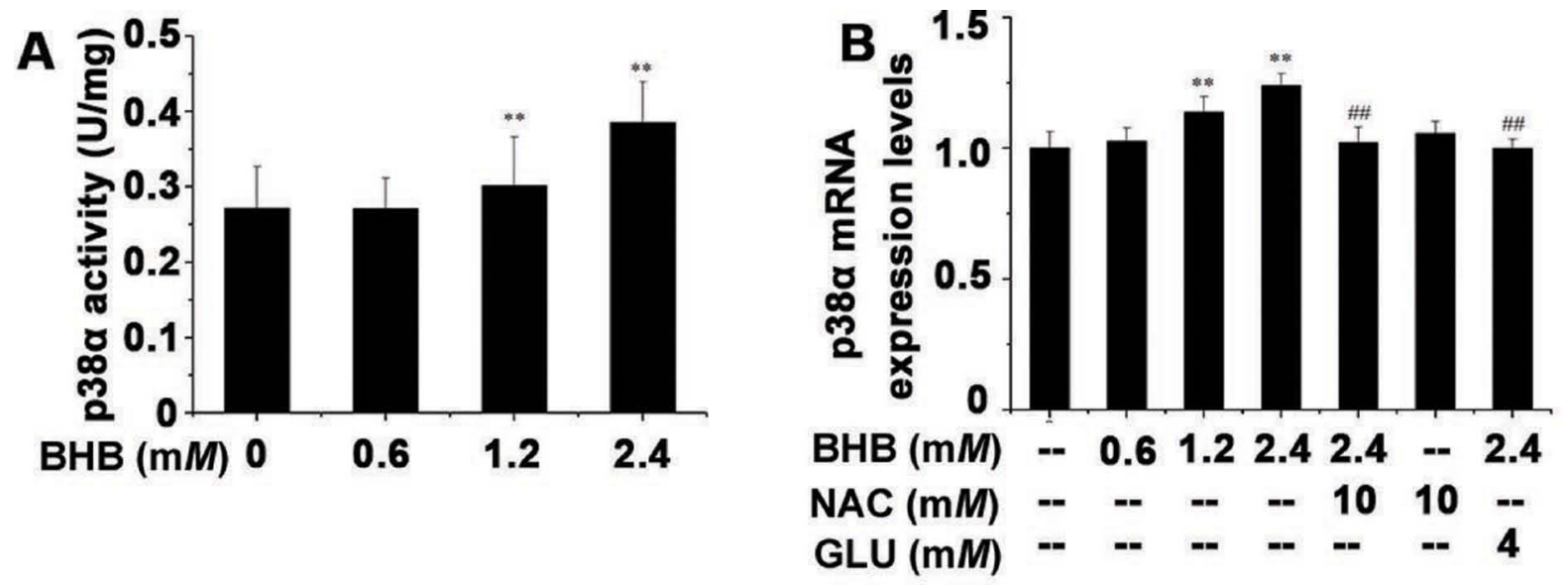

C

BHB (mM) $\quad 0 \quad 0.61 .22 .4$

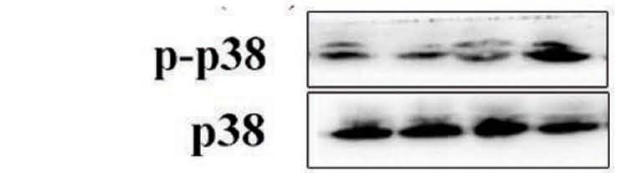

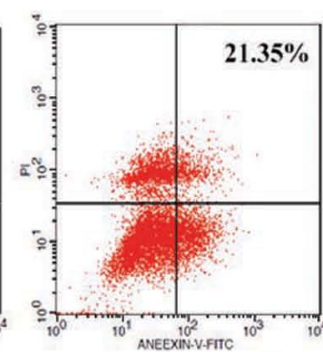
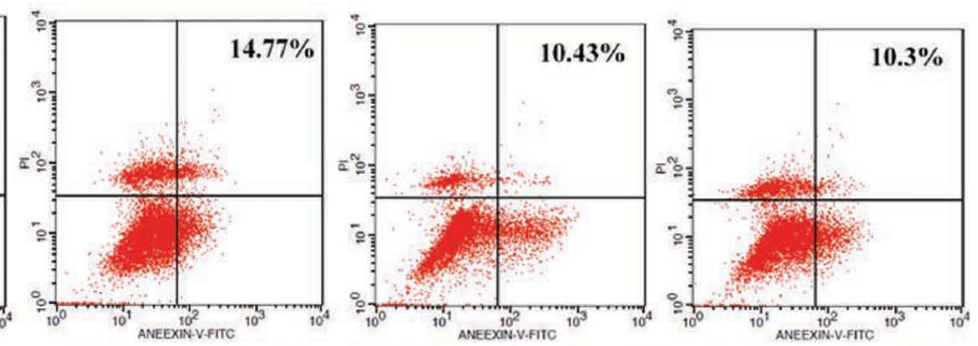

BHB (0 mM)

BHB (2.4 mM)

BHB $(2.4 \mathrm{mM})$
$+\mathrm{SB} 203580(10 \mu M)$
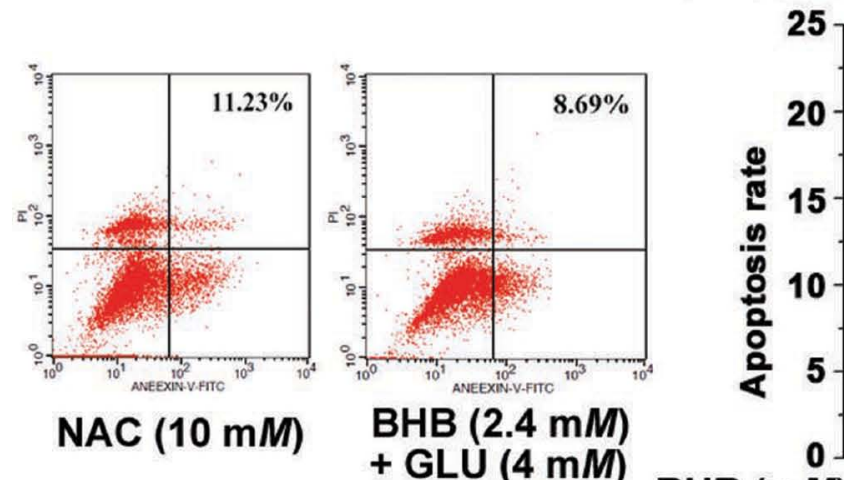

SB203580 (10 $\mu M)$

BHB $(2.4 \mathrm{mM})$

+ NAC (10 mM)

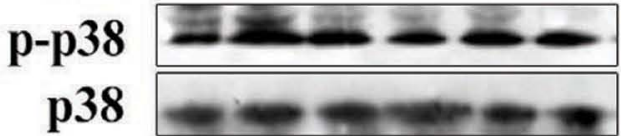

NAC $(10 \mathrm{~m} M)$

$\begin{array}{llllllll}\mathrm{BHB}(\mathrm{m} M) & - & 2.4 & 2.4 & - & 2.4 & - & 2.4\end{array}$

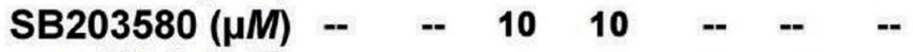

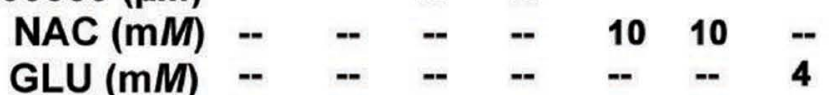

Figure 3. The p38 mitogen-activated protein kinases (MAPK) signaling pathway is implicated in the hepatocyte apoptosis caused by BHB. The hepatocytes were treated with different concentrations of BHB $(0,0.6,1.2$, and $2.4 \mathrm{~m} M)$, N-acetyl-L-cysteine (NAC; $10 \mathrm{~m} M)$, glucose (GLU; $4 \mathrm{mM}$ ), and SB203580 (p38 inhibitor; $10 \mu \mathrm{M}$ ), respectively. (A) The activity of p38 in bovine hepatocytes; (B) mRNA expression level of p38 in bovine hepatocytes; (C and D) phosphorylation level of $p 38$ in bovine hepatocytes; and (E) apoptotic rates of hepatocytes. Results are expressed as means \pm SEM. ${ }^{* *} P<0.01$ versus the control group $(0 \mathrm{mMBHB})$; \#\#P<0.01 versus the $2.4 \mathrm{~m} M$ BHB group. Color version available online. 

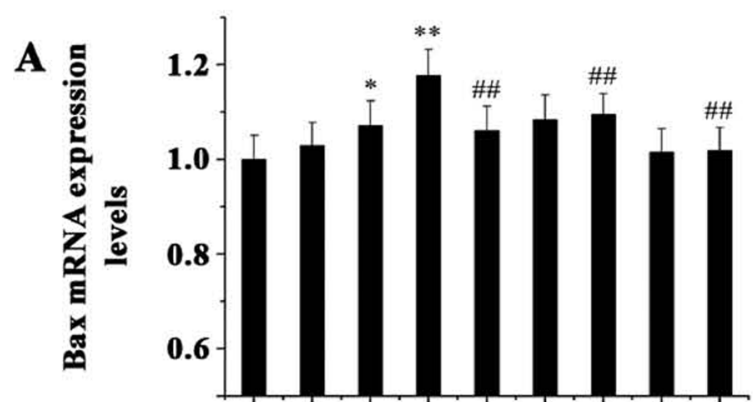

BHB $(\mathrm{m} M)-0.6 \quad 1.22 .42 .4--2.4-2.4$

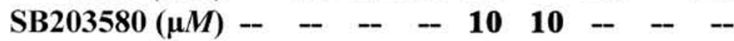

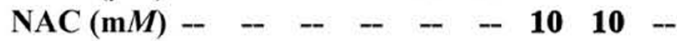

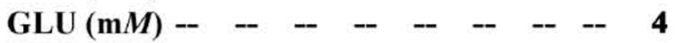
C

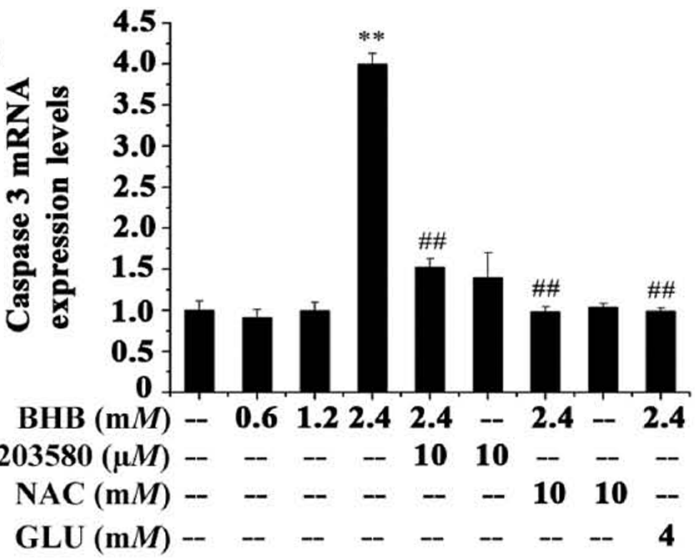

B .
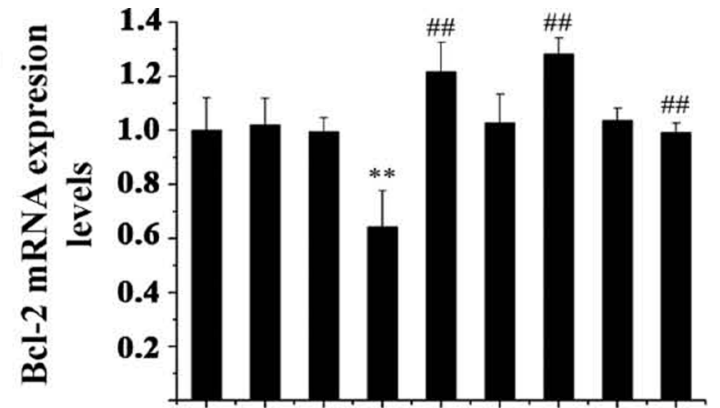

BHB $(\mathrm{m} M)-0.6 \quad 1.22 .42 .4 \quad-\quad 2.4 \quad-\quad 2.4$

SB203580 $(\mu M)$ -

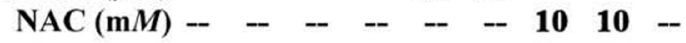

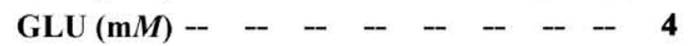

D

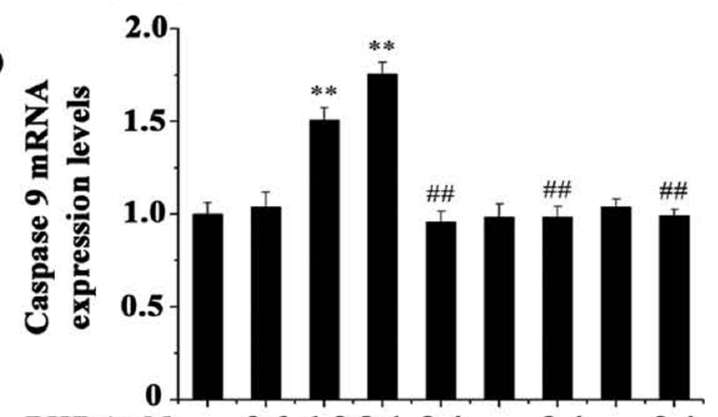

$\mathrm{BHB}(\mathrm{m} M)-0.61 .22 .42 .4-2.4-2.4$

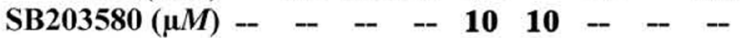

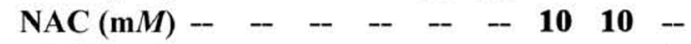

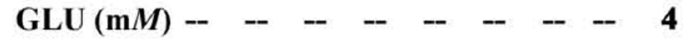

F

$$
\begin{array}{lllllll}
\text { GLU }(\mathrm{m} M) & -- & -- & -- & -- & 4 & 4 \\
\text { NAC }(\mathrm{m} M) & -- & -- & 10 & 10 & -- & -- \\
\text { BHB }(\mathrm{m} M) & 0 & 2.4 & 2.4 & 0 & 2.4 & 0
\end{array}
$$

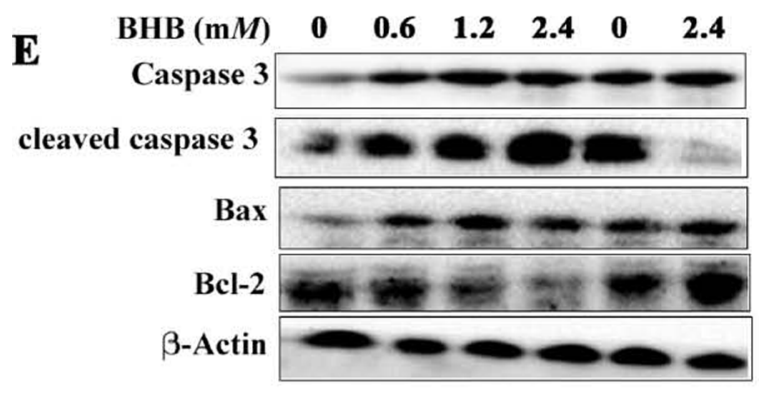

cleaved caspase 3
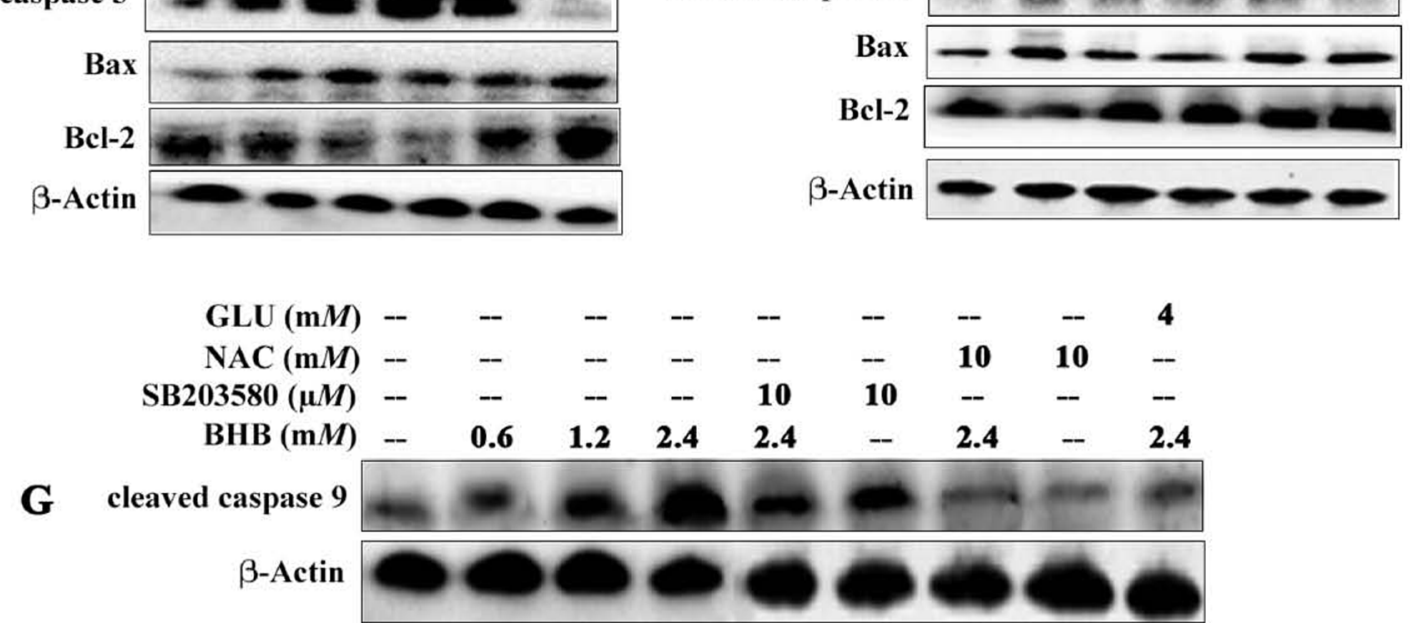

Figure 4. Reactive oxygen species (ROS)-p38 pathway involved in BHB-induced hepatocyte apoptosis. The hepatocytes were treated as described in Figure 3. (A-D) The mRNA expression levels of Bax, Bcl-2, caspase 3, and caspase 9; (E-F) protein expression levels of caspase 3, caspase 9, Bax, and Bcl-2 and the activation levels of the apoptosis-related proteins cleaved caspase 3 and cleaved caspase 9. Results are expressed as means \pm SEM. ${ }^{*} P<0.05,{ }^{* *} P<0.01$ versus the control group $(0 \mathrm{~m} M \mathrm{BHB})$; \#\# $P<0.01$ versus the $2.4 \mathrm{~m} M$ BHB group. NAC $=\mathrm{N}$-acetyl-L-cysteine; SB203580 = p38 inhibitor; GLU = glucose. 
The hepatocytes of ketotic cows were exposed to an oxidative stress induced by high BHB levels. p38 MAPK is a vital transduction mediator that responds to a wide range of extracellular stresses, including oxidative stress, and as a sensor of ROS (Tormos et al., 2013). Here, our results showed that high concentrations of BHB significantly increased p38 mRNA expression levels, p38 protein phosphorylation levels, and activity, but GLU and NAC significantly inhibited the expression and activation of p38 caused by BHB. Importantly, high concentrations of BHB significantly increased the apoptosis rate of hepatocytes, but the p38 inhibitor SB203580, NAC, and GLU significantly inhibited BHB-induced apoptosis in hepatocytes. These results indicate that the hepatocyte apoptosis caused by BHB was mediated by the ROS-p38 pathway. Furthermore, the effects of high concentrations of BHB on the expression of pro-apoptosis (Bax, caspase 3 , and caspase 9 ) and anti-apoptosis ( $B c l-2)$ genes also demonstrated that BHB-induced hepatocytes apoptosis through ROS-p38 pathway. In ketotic cows, the p38 signaling pathway may play an important role in the apoptosis damage caused by high concentrations of BHB. In addition, Gessner et al. (2014) found that endoplasmic reticulum (ER) stress was induced in the liver of dairy cow during the periparturient phase by detecting the expression level of ER stress molecule XBP1. Furthermore, it has been shown that p38MAPK signal pathway can be activated by ER stress inducer Tunicamycin and brefeldin A in ML-1 or MCF-7 cells (Hung et al., 2004), which indicated that ER stress could activate p38MAPK signal pathway and induce apoptosis. Accordingly, high levels of BHB may induce ER stress and then aggravate apoptosis in ketotic cows.

We know that p38 mediates cell death or survival by regulating downstream transcription factors, including p53 and Nrf2, which are redox-sensitive transcription factors (Liu et al., 2009; Circu and Aw, 2010). This study demonstrated that p53 could be activated by p38, which stabilizes p53 and promotes its accumulation in the nucleus, resulting in the regulation of the expression of its target genes (e.g., Bax, Bak, Puma, Noxa, and Apaf1; Wei et al., 2006). Nrf2 is a key regulatory factor that protects cells from oxidative stress. A previous study found that p38 is involved in regulating the phosphorylation of Nrf2 by promoting the dissociation of Nrf2 from the Nrf2-Keap1 complex either by phosphorylating Nrf2 directly or phosphorylating intermediary kinases (Martin et al., 2004). This process permits the accumulation of liberated Nrf2 in the nucleus,

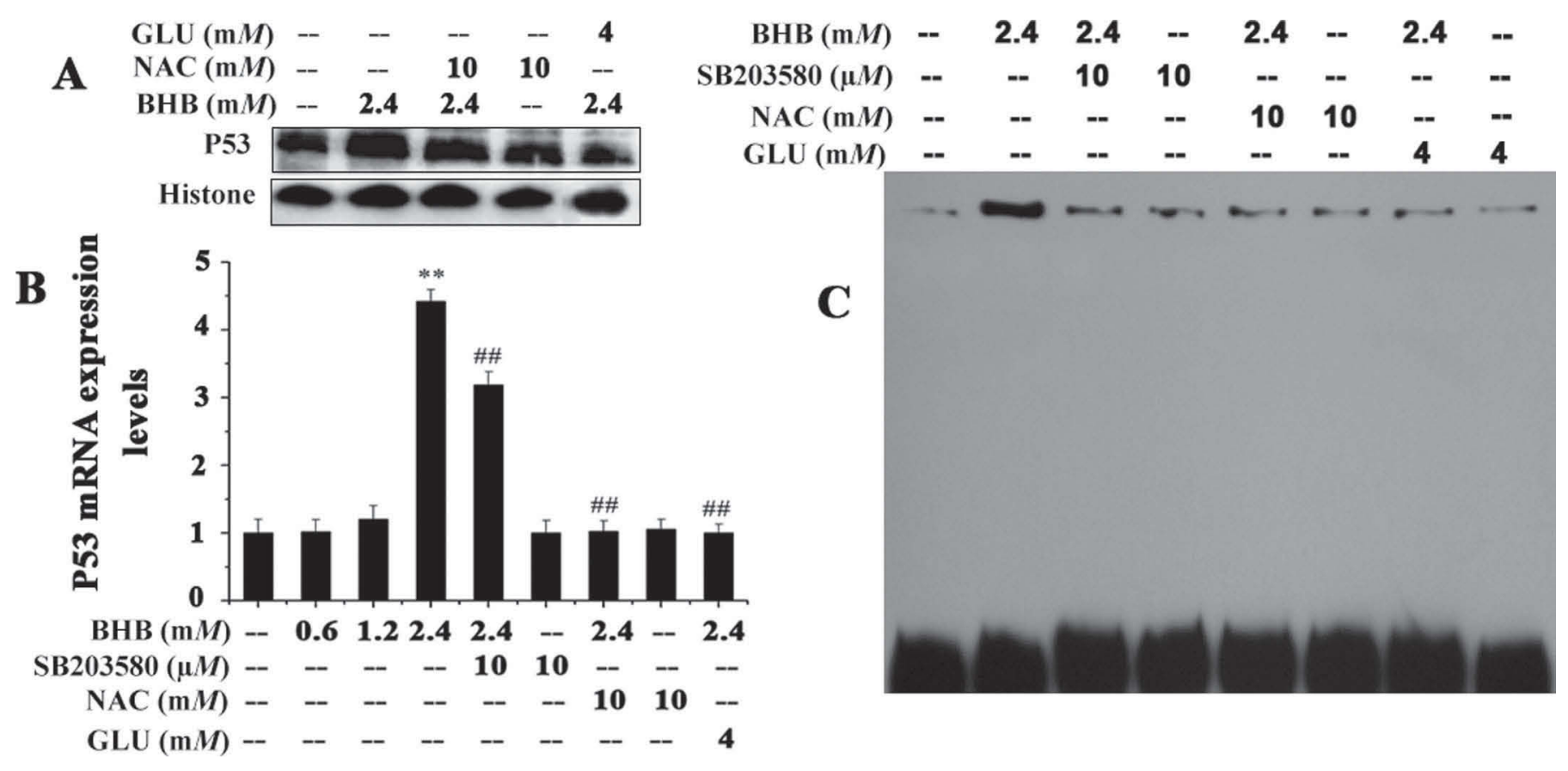

Figure 5. The effects of BHB on the expression and transcriptional activity of p53 in bovine hepatocytes. The hepatocytes were treated with BHB $(2.4 \mathrm{mM}$ ), N-acetyl-L-cysteine (NAC; $10 \mathrm{mM}$ ), glucose (GLU; $4 \mathrm{mM}$ ), and SB203580 (p38 inhibitor; $10 \mu M$ ). (A) Nuclear p53 protein expression levels were detected by Western blot; (B) p53 mRNA expression levels were detected by quantitative real-time PCR; and (C) transcriptional activity of nuclear p53 determined by an electrophoretic mobility shift assay. Results are expressed as means \pm SEM. $* * P<0.01$ versus the control group $(0 \mathrm{~m} M \mathrm{BHB})$; \#\#P $<0.01$ versus the $2.4 \mathrm{~m} M$ BHB group. 


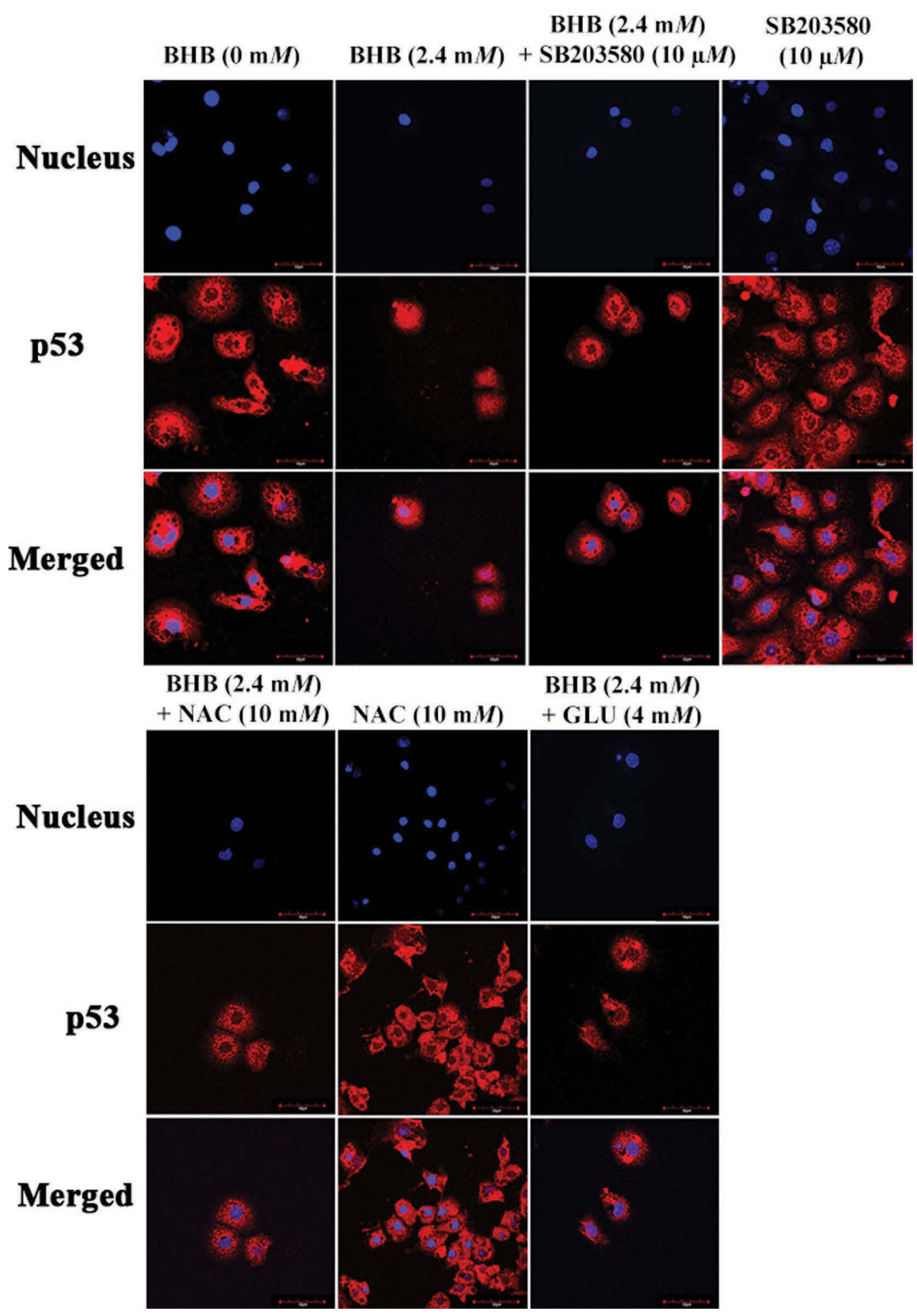

Figure 6. The effects of BHB on the nuclear localization of p53 in bovine hepatocytes. The hepatocytes were treated as described in Figure 5. p53 cellular localization was analyzed by immunofluorescence using laser confocal microscopy $(\times 600)$. NAC $=$ N-acetyl-L-cysteine; SB203580 $=$ p38 inhibitor; GLU = glucose. Color version available online. 


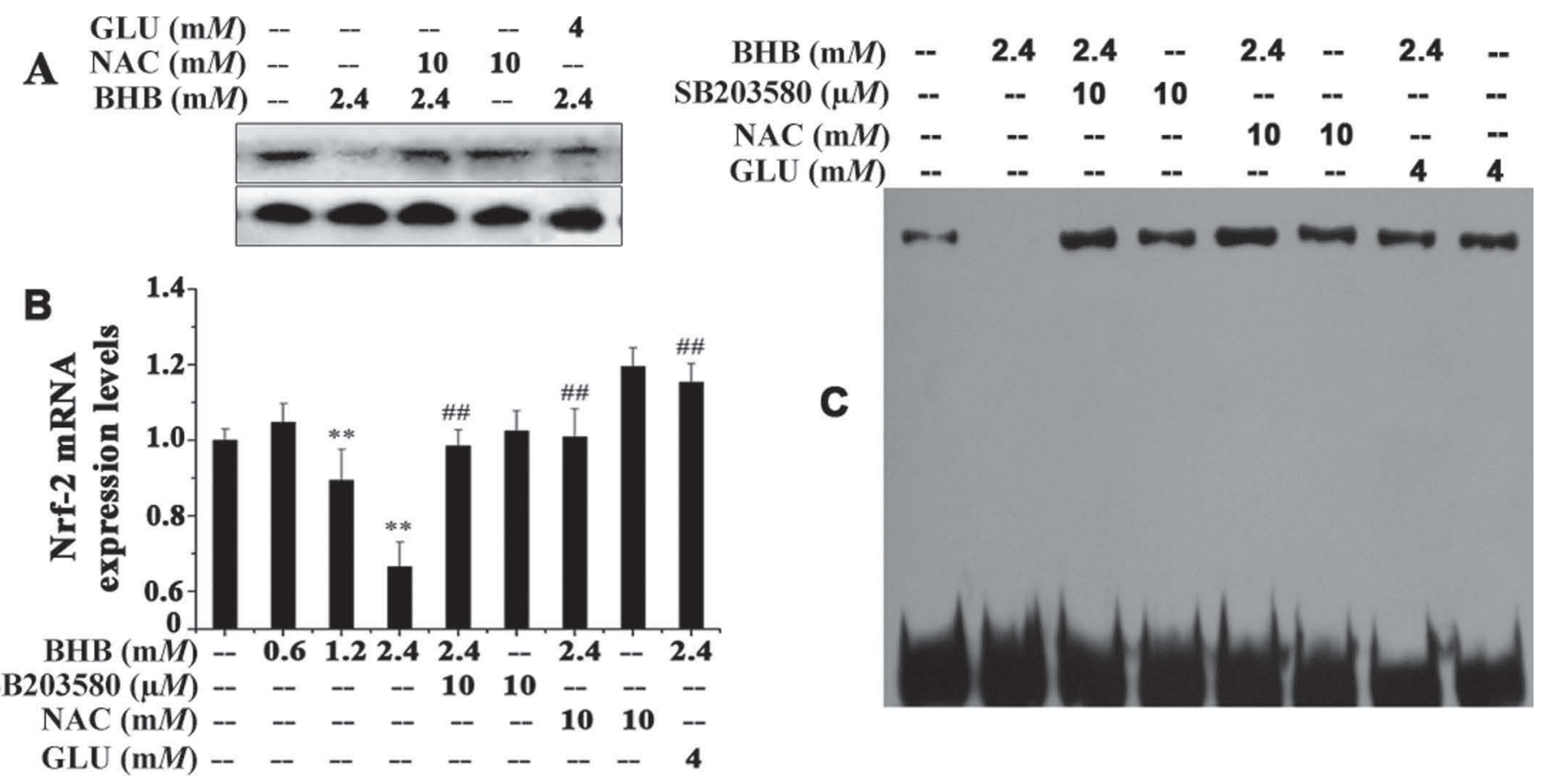

Figure 7. The effects of BHB on the expression and transcriptional activity of nuclear factor E2-related factor 2 (Nrf2) in bovine hepatocytes. The hepatocytes were treated as described in Figure 5. (A) Nuclear Nrf2 protein levels were detected by Western blot; (B) mRNA expression levels of Nrf2 detected by quantitative real-time PCR; and (C) transcriptional activities of Nrf2 determined by an electrophoretic mobility shift assay. Results are expressed as means \pm SEM. ${ }^{* *} P<0.01$ versus the control group $(0 \mathrm{~m} M$ BHB $)$; \#\#P<0.01 versus the $2.4 \mathrm{~m} M$ BHB group. NAC $=$ N-acetyl-L-cysteine; SB203580 $=$ p38 inhibitor; GLU $=$ glucose.

which then regulates the expression of some antioxidant target genes. In the current study, we found that high concentrations of BHB increased the expression level, transcriptional activity, and nuclear localization of p53. Interestingly, SB203580, NAC, and GLU countered the effects of BHB on $\mathrm{p} 53$. These results demonstrated that BHB could further activate p53 through ROS-p38 pathway. In addition, we found that the effects of BHB on the Nrf- 2 showed reverse results. Both p53 and Nrf2 are key transcription factors downstream of p38 in bovine hepatocytes treated with BHB. Additional evidence showed that Nrf2 and p53 are competitors for the same DNA promoter regions, and p53 can suppress the transcriptional activity of Nrf2 (Faraonio et al., 2006); this may also be a way of regulating BHB-ROS-p38 to Nrf2. It was noteworthy that periparturient phase of dairy cows showed a proinflammatory condition in the liver and with increased mRNA expression level of Nrf2 target genes (Gessner et al., 2013). This study further demonstrated the antioxidative and cytoprotective role of Nrf-2 in keeping balance between confrontation and promotion of oxidative stress and inflammation in the periparturient phase of dairy cows. According to our study, when ketosis occurred in dairy cows, hepatocytes was exposed to high levels of BHB, which might result in an inhibition of Nrf2 by a ROS-p38 pathway in hepatocytes and lead to hepatocytes apoptosis. However, more evidence is required to identify the involved molecular mechanisms more accurately.

In summary, our results suggest that BHB significantly correlates with oxidative stress and liver apoptosis damage in dairy cows with ketosis. High levels of BHB induced oxidative stress and then apoptosis in bovine hepatocytes through ROS-p38-p53/Nrf2 pathway. These findings will promote new exploration into the prevention and treatment of some metabolic disorders, such as ketosis and fatty liver, which are induced by BHB in dairy cows with an NEB.

\section{ACKNOWLEDGMENTS}

This work was supported by the National Key Technology R\&D Program (Beijing, China; grant no. 2012BAD12B03 and 2013BAD21B01), the National High Technology Research and Development Program 863 (Beijing, China; grant no. 2013AA102806), the National Natural Science Foundation of China (Beijing, China; grant nos. 31360630, 31372494, 31402265, 31472247, 31460681, and 31572581). 

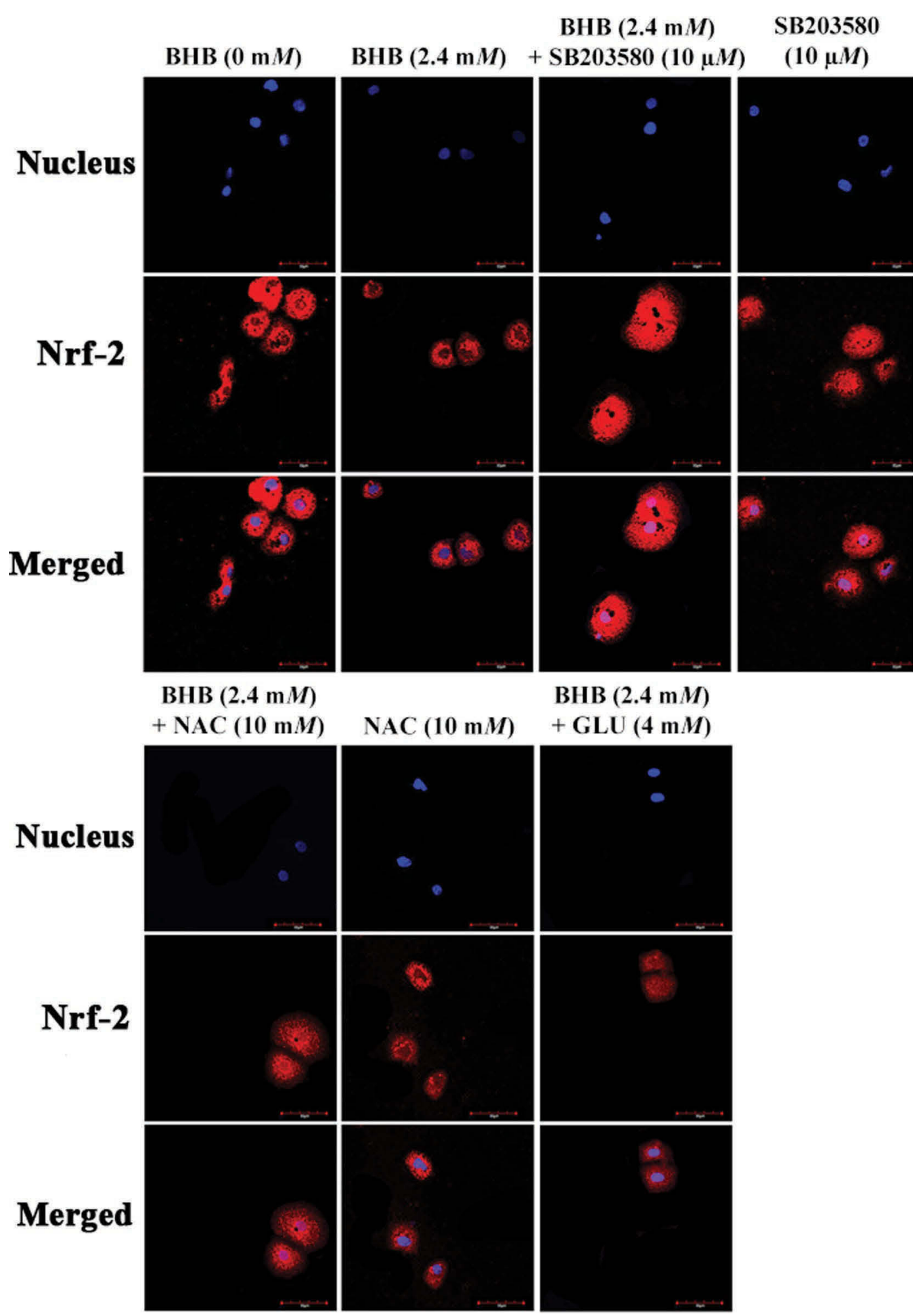

Figure 8. The effects of BHB on the nuclear localization of nuclear factor E2-related factor 2 (Nrf2) in bovine hepatocytes. The hepatocytes were treated as described in Figure 5 . The Nrf2 cellular localization was detected by immunofluorescence using laser confocal microscopy ( $\times 600)$. $\mathrm{NAC}=\mathrm{N}$-acetyl-L-cysteine; SB203580 = p38 inhibitor; GLU = glucose. Color version available online . 


\section{REFERENCES}

Castillo, C., J. Hernandez, A. Bravo, M. Lopez-Alonso, V. Pereira, and J. L. Benedito. 2005. Oxidative status during late pregnancy and early lactation in dairy cows. Vet. J. 169:286-292.

Castillo, C., J. Hernandez, I. Valverde, V. Pereira, J. Sotillo, M. L. Alonso, and J. L. Benedito. 2006. Plasma malonaldehyde (MDA) and total antioxidant status (TAS) during lactation in dairy cows. Res. Vet. Sci. 80:133-139.

Circu, M. L., and T. Y. Aw. 2010. Reactive oxygen species, cellular redox systems, and apoptosis. Free Radic. Biol. Med. 48:749-762.

Duffield, T. 2000. Subclinical ketosis in lactating dairy cattle. Vet Clin. North Am. Food Anim. Pract. 16:231-253.

Faraonio, R., P. Vergara, D. Di Marzo, M. G. Pierantoni, M. Napolitano, T. Russo, and F. Cimino. 2006. p53 suppresses the Nrf2dependent transcription of antioxidant response genes. J. Biol. Chem. 281:39776-39784.

Gessner, D. K., G. Schlegel, J. Keller, F. J. Schwarz, R. Ringseis, and K. Eder. 2013. Expression of target genes of nuclear factor E2related factor 2 in the liver of dairy cows in the transition period and at different stages of lactation. J. Dairy Sci. 96:1038-1043.

Gessner, D. K., G. Schlegel, R. Ringseis, F. J. Schwarz, and K. Eder. 2014. Up-regulation of endoplasmic reticulum stress induced genes of the unfolded protein response in the liver of periparturient dairy cows. BMC Vet. Res. 10:46.

Grummer, R. R. 2008. Nutritional and management strategies for the prevention of fatty liver in dairy cattle. Vet. J. 176:10-20.

Hammon, D. S., I. M. Evjen, T. R. Dhiman, J. P. Goff, and J. L. Walters. 2006. Neutrophil function and energy status in Holstein cows with uterine health disorders. Vet. Immunol. Immunopathol. $113: 21-29$.

Hawkins, R. A., and J. F. Biebuyck. 1979. Ketone bodies are selectively used by individual brain regions. Science 205:325-327.

Hung, J. H., I. J. Su, H. Y. Lei, H. C. Wang, W. C. Lin, W. T. Chang, W. Huang, W. C. Chang, Y. S. Chang, C. C. Chen, and M. D. Lai. 2004. Endoplasmic reticulum stress stimulates the expression of cyclooxygenase- 2 through activation of NF- $\kappa \mathrm{B}$ and pp38 mitogenactivated protein kinase. J. Biol. Chem. 279:46384-46392.

Iwersen, M., D. Klein-Jobstl, M. Pichler, L. Roland, B. Fidlschuster, I. Schwendenwein, and M. Drillich. 2013. Comparison of 2 electronic cowside tests to detect subclinical ketosis in dairy cows and the influence of the temperature and type of blood sample on the test results. J. Dairy Sci. 96:7719-7730.

Jaiswal, A. K. 2004. Nrf2 signaling in coordinated activation of antioxidant gene expression. Free Radic. Biol. Med. 36:1199-1207.

LeBlanc, S. J., T. Osawa, and J. Dubuc. 2011. Reproductive tract defense and disease in postpartum dairy cows. Theriogenology $76: 1610-1618$

Li, X., W. Huang, J. Gu, X. Du, L. Lei, X. Yuan, G. Sun, Z. Wang X. Li, and G. Liu. 2015. SREBP-1c overactivates ROS-mediated hepatic NF- $\mathrm{B}$ inflammatory pathway in dairy cows with fatty liver. Cell. Signal. 27:2099-2109.

Liu, B., Y. Cheng, B. Zhang, H. J. Bian, and J. K. Bao. 2009. Polygonatum cyrtonema lectin induces apoptosis and autophagy in human melanoma A375 cells through a mitochondria-mediated ROS-p38-p53 pathway. Cancer Lett. 275:54-60.

Liu, L., X. Li, Y. Li, Y. Guan, Y. Song, L. Yin, H. Chen, L. Lei, J. Liu, X. Li, Z. Wang, X. Yang, and G. Liu. 2014. Effects of nonesterified fatty acids on the synthesis and assembly of very low density lipoprotein in bovine hepatocytes in vitro. J. Dairy Sci. 97:1328-1335.

Loor, J. J., R. E. Everts, M. Bionaz, H. M. Dann, D. E. Morin, R. Oliveira, S. L. Rodriguez-Zas, J. K. Drackley, and H. A. Lewin. 2007. Nutrition-induced ketosis alters metabolic and signaling gene networks in liver of periparturient dairy cows. Physiol. Genomics 32:105-116.
Martin, D., A. I. Rojo, M. Salinas, R. Diaz, G. Gallardo, J. Alam, C. M. De Galarreta, and A. Cuadrado. 2004. Regulation of heme oxygenase-1 expression through the phosphatidylinositol 3-kinase/Akt pathway and the Nrf2 transcription factor in response to the antioxidant phytochemical carnosol. J. Biol. Chem. 279:8919-8929.

McArt, J. A., D. V. Nydam, G. R. Oetzel, T. R. Overton, and P. A. Ospina. 2013. Elevated non-esterified fatty acids and betahydroxybutyrate and their association with transition dairy cow performance. Vet. J. 198:560-570.

Noh, H. S., Y. S. Hah, R. Nilufar, J. Han, J. H. Bong, S. S. Kang, G. J. Cho, and W. S. Choi. 2006. Acetoacetate protects neuronal cells from oxidative glutamate toxicity. J. Neurosci. Res. 83:702-709.

Pedernera, M., P. Celi, S. C. Garcia, H. E. Salvin, I. Barchia, and W J. Fulkerson. 2010. Effect of diet, energy balance and milk production on oxidative stress in early-lactating dairy cows grazing pasture. Vet. J. 186:352-357.

She, Q. B., N. Chen, and Z. Dong. 2000. ERKs and p38 kinase phosphorylate p53 protein at serine 15 in response to UV radiation. J. Biol. Chem. 275:20444-20449.

Shi, X., X. Li, D. Li, Y. Li, Y. Song, Q. Deng, J. Wang, Y. Zhang, H. Ding, L. Yin, Y. Zhang, Z. Wang, X. Li, and G. Liu. 2014 $\beta$-Hydroxybutyrate activates the NF- $\mathrm{kB}$ signaling pathway to promote the expression of pro-inflammatory factors in calf hepatocytes. Cell. Physiol. Biochem. 33:920-932.

Shimazu, T., M. D. Hirschey, J. Newman, W. He, K. Shirakawa, N. Le Moan, C. A. Grueter, H. Lim, L. R. Saunders, R. D. Stevens, C. B. Newgard, R. V. Farese Jr., R. de Cabo, S. Ulrich, K. Akassoglou, and E. Verdin. 2013. Suppression of oxidative stress by beta-hydroxybutyrate, an endogenous histone deacetylase inhibitor. Science 339:211-214.

Song, Y., X. W. Li, Y. Li, N. Li, X. X. Shi, H. Y. Ding, Y. H. Zhang, X. B. Li, G. W. Liu, and Z. Wang. 2014. Non-esterified fatty acids activate the ROS-p38-p53/Nrf2 signaling pathway to induce bovine hepatocyte apoptosis in vitro. Apoptosis 19:984-997.

Tharwat, M., D. Endoh, and S. Oikawa. 2012a. Hepatocyte apoptosis in dairy cows with fatty infiltration of the liver. Res. Vet. Sci. 93:1281-1286.

Tharwat, M., A. Takamizawa, Y. Z. Hosaka, D. Endoh, and S. Oikawa. 2012b. Hepatocyte apoptosis in dairy cattle during the transition period. Can. J. Vet. Res. 76:241-247.

Tormos, A. M., R. Talens-Visconti, A. R. Nebreda, and J. Sastre. 2013. p38 MAPK: A dual role in hepatocyte proliferation through reactive oxygen species. Free Radic. Res. 47:905-916.

Walsh, R. B., J. S. Walton, D. F. Kelton, S. J. LeBlanc, K. E. Leslie, and T. F. Duffield. 2007. The effect of subclinical ketosis in early lactation on reproductive performance of postpartum dairy cows. J. Dairy Sci. 90:2788-2796.

Wathes, D. C., Z. Cheng, M. A. Fenwick, R. Fitzpatrick, and J. Patton. 2011. Influence of energy balance on the somatotrophic axis and matrix metalloproteinase expression in the endometrium of the postpartum dairy cow. Reproduction 141:269-281.

Wei, C. L., Q. Wu, V. B. Vega, K. P. Chiu, P. Ng, T. Zhang, A. Shahab, H. C. Yong, Y. Fu, Z. Weng, J. Liu, X. D. Zhao, J. L. Chew, Y. L. Lee, V. A. Kuznetsov, W. K. Sung, L. D. Miller, B. Lim, E. T. Liu, Q. Yu, H. H. Ng, and Y. Ruan. 2006. A global map of p53 transcription-factor binding sites in the human genome. Cell 124:207-219.

Wullepit, N., M. Hostens, C. Ginneberge, V. Fievez, G. Opsomer, D. Fremaut, and S. De Smet. 2012. Influence of a marine algae supplementation on the oxidative status of plasma in dairy cows during the periparturient period. Prev. Vet. Med. 103:298-303.

Youssef, M. A., S. A. El-Khodery, W. M. El-deeb, and W. E. Abou ElAmaiem. 2010. Ketosis in buffalo (Bubalus bubalis): clinical findings and the associated oxidative stress level. Trop. Anim. Health Prod. 42:1771-1777. 